\title{
Toxicologia do tolueno: aspectos relacionados ao abuso
}

\author{
Toluene toxicology: abuse aspects
}

\author{
Letícia M.K. Forster*, Mario Tannhauser*, Semíramis L.Tannhauser*
}

FORSTER, L.M.K. et al. Toxicologia do tolueno: aspectos relacionados ao abuso. Rev. Saude Pública, 28: 167. 72, 1994. O tolueno está presente em muitos produtos de uso doméstico e industrial e é o principal solvente cnvolvido no abuso de substâncias e na exposição ocupacional. O problema mais grave no estudo de patologias relacionadas ao tolueno é que este está geralmente associado, em suas preparações comerciais, a outras substâncias. O potencial tóxico do tolueno foi abordado nos seguintes aspectos: parâmetros farmacológicos; caracteristicas fisico-químicas; exposição; estudos clínicos; diagnóstico; pesquisa experimental; tolerância e dependência; efeitos agudos e crônicos; neurotoxicidade; teratogenicidade; doenças psiquiátricas; carcinogenicidade e tratamento. Conclui-se ser de grande importância e urgência que se realizem estudos clínicos com amostras maiores para definição mais precisa das conseqüências do uso crônico

Descritores: Tolueno, toxicidade. Exposição ocupacional. Abuso de substâncias.

\section{Histórico}

A inalação voluntária de substâncias com o propósito de alterar o humor era uma prática comum já nos tempos mais remotos da nossa civilização. Os anciãos hebreus utilizavam a inalação de gases frios que emanavam das fendas das rochas como parte de um culto. Nativos da América do Sul empregaram, por séculos, rapés semelhantes a alucinógenos em cerimônias religiosas para marcar ritos de passagem dos jovens ${ }^{5,29}$.

No século passado, o pintor Van Gogh (1853-1890) inalava terebentina, derivado do petróleo usado como solvente de tintas ${ }^{6}$.

Em 1940, foi iniciada a produção e uso generalizado de solventes para fins industriais, porém, somente muitos anos depois vieram à tona os problemas ocupacionais relacionados a essas substâncias. Somente em 1984 , aproximadamente 49 milhões de toneladas de solventes industriais foram produzidos nos Estados Unidos. Chegaram a existir $\mathrm{em}$ torno de 10 milhões de trabalhadores expostos a solventes orgânicos nas indústrias num período de um ano ${ }^{7}$.

\footnotetext{
* Fundação Faculdade Federal de Ciências Médicas de Porto Alegre - Porto Alegre, RS - Brasil Separatas/Reprints: L.M.K.Forster - R. Artigas, 370 - 90670 120 - Porto Alegre, RS - Brasil
}

Nos Estados Unidos, o fenômeno do abuso de solventes teve início na década de 60 , e na Inglaterra no ano de 1970 foi registrada uma morte relacionada ao abuso dessas substâncias, tomando proporções alarmantes em 1988 (134 mortes/ano) e havendo tendência geral de aumento. No caso especílico do tolueno (principal componcnte em adesivos) as mortes eram principalmente causadas por acidentes (39\%) e não pelos efeitos tóxicos diretos que contribuíram com apenas $19 \%$ do total das causas de óbito. Ainda na Inglaterra, um estudo epidemiológico sobre mortes por abuso de substâncias voláteis mostrou que todas as classes sociais estavam envolvidas com este problema havendo predominância do sexo masculino (95\%), não especificamente em relação ao abuso, mas aos óbitos $1,4,5,10,17,29,30,47$. No Brasil o primeiro levantamento nacional sobre consumo de drogas entre estudantes de primeiro e segundo graus da rede pública foi realizado em 1987 , sendo os solventes o grupo de drogas de uso ilícito mais consumido; este dado foi confirmado $\mathrm{cm}$ outro levantamento realizado em $1989^{8,27}$. Entre "meninos de rua" o trabalho mais recente também aponta o grupo dos solventes como o de maior consumo, após o álcool e o tabaco ${ }^{18}$.

O objetivo do presente trabalho é relatar, com base na literatura, os principais aspectos relativos ao potencial tóxico do tolueno e as consequências de seu uso. 


\section{Características Físico-químicas e Parâmetros Farmacológicos}

O solvente em questão, o tolueno ou metilbenzeno, é um hidrocarboneto aromático, incolor e de odor característico. Sua fórmula é $\mathrm{C}_{6} \mathrm{H}_{5} \mathrm{CH}_{3}$ e possui peso molecular de 92,15 . Esta substância sofre ebulição a $110,6^{\circ} \mathrm{C}$; sua pressĩo de vapor é de $22 \mathrm{mmHg}$ a $20^{\circ} \mathrm{C}$; se autoinflama a $480^{\circ} \mathrm{C}$; e o limiar de odor dos vapores de tolueno ocorre entre 0,04 e $1 \mathrm{mg} / 1$ na água e $8 \mathrm{mg} / \mathrm{m}^{3}$ no $\mathrm{ar}^{40}$.

Os solventes, do ponto de vista toxicológico, são substâncias orgânicas, lipossolúveis que atravessam a barreira hematoencefálica com facilidade produzindo uma alteração no estado de consciência, similar aos níveis mais leves de anestesia $^{14,36}$. A principal via de introdução é o sistema respiratório, pois tendo os vapores atingido os pulmões podem facilmente se difundir ao longo de uma ampla superficie e penctrar na corrente sanguínea. A segunda via potencial de exposição é a pele e sua taxa de absorção varia de 14 a $23 \mathrm{mg} / \mathrm{cm}^{2} / \mathrm{h}$, podendo ocorrer ressecamento e irritação da mesma ${ }^{2}$.

Os produtos metabólicos do tolueno sĩo o cresol (menos de 1\%) e o metabólito intermediário benzaldeído. O benzaldeído é metabolizado a ácido benzóico o qual se conjuga com a glicina e forma o ácido hipúrico. Em humanos, mais de $75 \%$ do tolueno inalado é metabolizado a ácido hipúrico e é excretado na urina 12 horas após a exposição ${ }^{17,40}$. Alguns trabalhos incluem dosagens desse metabólito para confirmação da efetividade da exposição ao tolucno ${ }^{32,41}$. Porém outros autores afirmam que não há valor diagnóstico nas dosagens de ácido hipúrico pois este é um constituinte normal da urina e pode ser influenciado pela dieta, sugerindo então dosagens diretas de tolueno no sangue. No entanto, é importante que se observe o intervalo entre a exposição ao tolueno e a coleta da amostra. Concentrações de tolueno podem ser bifásicas; um pico inicial é seguido por uma baixa refletindo ligação ao lipídios no sistema nervoso central e um pico subseqüente pode ocorrer em decorrência da liberação lenta do tolueno na corrente sangüínea. O exame pode ser positivo mesmo muitos dias após a retirada do tolueno ${ }^{24}$. Níveis plasmáticos de tolueno têm sido obtidos em autopsias após morte decorrente do abuso de tolueno por via inalatória. O tolueno é clistribuído nos tecidos ricos cm gordura e tecidos altamente vascularizados após a absorção, e é encontrado em concentrações 80 vezes maiores nos tecidos gordurosos do que no sangue. Esses tecidos incluem o cérebro, particularmente a susbtância branca, a medula óssea, figado, rins e tecidos nervo$\operatorname{sos}^{24,40}$. As concentrações de gases no ar são expressas em volume/volume, como por exemplo vol\%, partes por milhão (ppm) e outros 2,14 .

Um principio fundamental em toxicologia é de que a rclação dosc-resposta requer que haja exposição e cfcito tóxico. O potencial para intoxicação aumenta à medicla que a exposição aumenta, e a exposição a misturas de solventes leva à possibilidade de efeito aditivo, sinérgico ou potenciador imprevisíveis ${ }^{2}$.

Sabe-se que o tolueno é um depressor do sistema nervoso central (SNC), mas seu mecanismo dc ação ainda não é bem conhecido. Foi observado que ele provoca uma fase inicial de excitação seguida de depressão leve à intensa, à semelhança do que ocorre com o álcool ${ }^{30}$.

\section{Exposição}

O tolueno está prescnte nas colas, gasolinas, solventes, agcntes de limpeza, entre outros. É também utilizado como produto químico "iniciador" na síntese de outros produtos químicos orgânicos, tais como o uretano, poliuretano e benzeno. O tolueno cstá naturalmente presente no óleo cru e é produziclo através do refinamento de petróleo como subproduto da produção de estireno. $\Lambda$ exposição humana ao tolucno ocorre a partir do uso ocupacional, no ambiente doméstico, através da inalação com fins de abuso e da exposição ambiental. A maior fonte de exposição ambiental ao tolueno é a produção e uso da gasolina. Grandes quantidades de tolueno são introduzidas no ambiente anualmente através do uso da gasolina e da produção e processos de refinamento de petróleo. Calcular os níveis de exposição humana provenientes do ar, do solo e da água pode ser dificil. No entanto, pesquisas realizadas nos Estados Uniclos por órgãos de fiscalização, detectaram que a maioria das pessoas está mais exposta ao tolueno no ambiente doméstico do que em qualquer outro 40 . 


\section{Pesquisas Clínicas}

$O$ interesse pela pesquisa com solventes vem aumentando nos últimos dez anos, pois surgiram muitos problemas de saúde relacionados à exposição ocupacional dessas substâncias. Proliferaram os estudos clínicos a respeito deste problema, agora não só relacionado à exposição ocupacional como também ao abuso de solventes, tais como o tolueno. Apesar de já existirem inúmeras publicações sobre o assunto, descrevendo alterações clínicopatológicas, observa-se na literatura carência de séries com grande número de pacientes ${ }^{45}$.

A exemplo disso, Kaelan e col. ${ }^{22}$ descreveram as alterações patológicas de intoxicação aguda em apenas um caso.

Rosenberg e col. ${ }^{35}$ fizeram estudo com seis abusadores crônicos de tolueno e verificaram: atrofia cerebral difusa; perda da diferenciação entre a substância branca e a cinzenta ao longo do SNC; e hiperintensidade periventricular da substância branca em T2.

col. ${ }^{16}$ utro trabalho, realizado por Filley e col. com 14 indivíduos, obteve achados patológicos bastante semclhantes aos citados na pesquisa descrita acima, principalmente no que se refere a alterações na substância branca. Algumas outras publicações confirmam os resultados descritos anteriormente, referindo-se mais a achados neuropatológicos que envolvem a bainha de miclina $20,21,24,25,29,34,39,46$.

Como já comentado, a principal causa de óbito entre inaladores de tolueno se relaciona a acidentes, tais como asfixia. Mortes súbitas de inaladores também ocorrem por arritmia cardíaca, resultante da ação das catecolaminas liberadas durante um exercício fisico em um miocárdio sensibilizado por inalantes utilizados, bem como por parada respiratória $1,11,12,17,34,43$.

\section{Modelos Animais}

Com o crescente abuso destas substâncias houve necessidade de se validar modelos experimentais para avaliar as manifestações patológicas a curto e a longo prazo. Muitos modelos de exposição foram propostos para simular a exposição ao tolueno via inalatória, uma vez que essa era a situação tanto no caso ocupacional como no de abuso $15,19,26,31,32,33,37,38,44$.

O modelo básico presente em todos os trabalhos com solventes pressupõe uma cuba (acrílico ou aço inoxidável) que varia de tamanho, com fluxo de ar contínuo, de onde se retira uma amostra para dosagem da concentração através de cromatografia gasosa, sendo que esta concentração é quase sempre expressa em partes por milhão (ppm). Conta ainda com uma aparclhagem bastante sofisticada que inclui filmadoras e computadores especialmente programados conectados com o sistema de exposição $23,26,31,32,44$.

As variações de um modelo para outro são na forma da exposição (aguda, subaguda, crônica); na concentração obtida (40-6.000 ppm); no número de animais por grupo em função do tamanho da cuba utilizada e do delineamento da pesquisa; no sexo e na idade dos animais dependendo dos objetivos do trabalho $19,26,31,32,44$.

Barnes 5 procurou descrever com detalhes as condições em que se efetua o abuso de solventes nos seres humanos, e o modelo experimental proposto por Pryor ${ }^{31}$ é o que mais se asscmclha à situação do uso de solventes com fins abusivos pelo esquema de exposição que é realizado.

\section{Diagnóstico}

O diagnóstico de uma síndrome tóxica é facilitado quando a exposição excede os níveis estabelecidos para efeitos biológicos e sintomas seguindo padrões clássicos para intoxicação. Mesmo em situações de toxicidade bem definida do SNC, reações psicológicas e emocionais podem influenciar a persistência de sintomas podendo complicar a recuperação. O diagnóstico diferencial de sintomas neuropsiquiátricos inclui: doenças mentais orgânicas; reações psicológicas ou emocionais secundárias à exposição e resultante doença; e doenças psiquiátricas pré-existentes ou concomitantes ${ }^{40}$.

O diagnóstico preciso de síndromes neuropsquiátricas associadas com exposição dependem de: história detalhada da exposição e cronologia de sintomas; conhecimento de possíveis efeitos neurotóxicos da exposição; avaliação psiquiátrica incluindo história psicossocial completa, história de uso de álcool e outras drogas, exame do estado mental e neurológico; 
e resultado de exames complementares, tais como testagem neuropsicológica, eletrencefalograma e neuroimagem ${ }^{40}$.

\section{Tolerância e Dependência}

Quanto aos quadros de tolerîncia e dependência existem algumas controvérsias na litcratura. No entanto, parece haver suficiente embasamento quanto ao desenvolvimento de tolcrância e dependência em decorrência do uso prolongado de colas $3,29,34$.

A dependência se manifesta por: fissura e/ou compulsão para obter ou consumir a droga; inquietação, ansiedade, e irritabilidade. Quando da retirada da droga também se pode observar um quadro de síndrome de abstinência onde surgem calafrios, cefaléia, alucinações, delirium tremens, dores abdominais e cãibras musculares $^{10,30,42}$.

\section{Efeitos Agudos}

Na exposição aguda ao tolueno podemos fazer uma correlação entre os níveis de exposição e efeitos decorrentes da mesma. Os efeitos da inalação voluntária variam muito $\mathrm{cm}$ severidade e duração dependendo da intensidade da exposição; a duração pode variar de 15 min a algumas horas. Com doses relativamente baixas (200 ppm) é descrita irritaçĩo dos olhos e garganta, podendo ocorrer lacrimejamento com doses maiores ( $400 \mathrm{ppm})$. Nessas mesmas doses, podese observar aumento do tempo de reação (visuomanual), sinais de incoordenação, celalćia, confusão, tonturas e sensação de intoxicação, quando a exposição se prolonga por mais de oito horas ${ }^{7}$.

Com doses crescentes (500-800 ppm), observa-se náusea, anorexia, confusão, hilariedade, perda do autocontrole, perdas momentâneas de memória, nervosismo, fadiga muscular, parestesia e insônia ${ }^{7}$.

Doses de 1.500 ppm ou mais causam efeitos agudos com exposições relativamente curtas (poucas horas ou minutos nas doses de 10.000 $30.000 \mathrm{ppm}$ ), como fraqueza acentuada, incoordenação e ataxia, euforia, às vezes alucinações, desorientação, até a narcose e morte com altas concentrações ${ }^{7}$.
Os efcitos agudos são reversíveis, mas tornam-se mais severos e persistentes com o aumento da concentração e/ou duração da exposição. Não se tem relatiado efeito tóxico em humanos expostos a níveis menores que $50 \mathrm{ppm}$ por curtos períodos de tempo ou expostos uma única vez a $100 \mathrm{ppm}$ por poucas horas. No entanto, há relatos de convulsõcs até mesmo chegando ao status epilcpticus, como primeira manifestaçĩo de intoxicação aguda por tolueno ${ }^{7}$.

\section{Neurotoxicidade}

Enccfialopatia tóxica aguda causada pclo tolucno pode cnvolver lctargia, alucinações e até coma, mas nomalmente este quadro se resolve completamente com a abstinência da droga. Abusadores crônicos podem apresentar cnccfalopatia persistente (crônica) envolvendo cérebro, tronco, nervo óptico e cercbelo. A síndrome de demência é caracterizada por apatia, desalençĩo e memória empobrecida. As corrclações clinicopatológicas são tão impressionantes que o abuso de tolueno parece constituir exemplo de modelo de Deméncia ${ }^{24,40}$.

\section{Teratogenicidade}

Exposição a solventes orgânicos, em geral, tem algum cfécito embriotóxico. O reconhecimento dessa associação levou à adoção da expressão "síndrome solvente fetal"; porém não foi possivel determinar o nivel de envolvimento do tolueno $\mathrm{em}$ tais achados em função das misturas a que as mulheres foram expostas ${ }^{40}$. No entanto, uma pesquisa rcalizada com trabalhadoras expostas a concentrações relativamente altas de tolucno (50-150 ppm), comparadas com outras da mesma indústria não expostas ou cxpostas a baixas concentrações $(0.25 \mathrm{ppm})$, não demonstrou correlação direta entre a exposição a esta substância e disfunções hemorrágicas uterinas 28 .

\section{Doenças Psiquiátricas}

A exposição a solventes pode ser relacionada com dois tipos de doenças mentais, doenças afctivas e psicose orgânica incapacitante ou degeneração cercbral . Uma pesquisa com 130 
abusadores de tolucno não mostrou existência de risco aumentado de desenvolvimento de depressão primária ou outras psicopatologias. Todavia, foi encontrado risco significativamente aumentado de diagnóstico de distúrbio anti-social de personalidade entre usuários de solventes ${ }^{13}$.

\section{Carcinogenicidade}

Não há estudo epidemiológico que indique que a exposição ao tolueno aumenta risco de carcinogênese. Estudos retrospectivos sobre mortalidade de trabalhadores expostos ao tolueno incluem outras substâncias químicas. Estudos animais também não demonstraram que o tolueno tenha efeitos carcinogênicos ${ }^{40}$.

\section{Tratamento}

O tratamento da toxicidade aguda de solventes é feito através de medidas padrão com ressuscitação cardiorrespiratória, quando necessário, tratamento convencional para arritmias e tratamento de suporte intensivo. Não existe antídoto específico para o tolueno. O manejo com abusadores crônicos é difícil, e o aconselhamento e técnicas psicoterápicas são muitas vezes necessários ${ }^{4,43}$.

\section{Considerações Finais}

Sendo o tolueno um dos principais solventes ao qual se está exposto, haveria necessidade de se realizar mais pesquisas com amostras maiores da população para que se possa definir, com maior clareza, as seqüelas do seu uso crônico. Os modelos experimentais são complexos e esclarecedores, mas de difícil extrapolação para os seres humanos devido às particularidades das condições do abuso de solventes. Poucos resultados foram obtidos nos estudos com animais no que se refere aos achados neuropatológicos, também havendo necessidade da ampliação deste tipo de pesquisa.

FORSTER, L.M.K. et al. [Toluene toxicology: abuse aspects]. Rev. Saúde Pública, 28: 167-72, 1994. Toluene, present in many industrial and domestic products, is the main solvent involved in solvent abuse and occupational exposure. The main problem in studying toluene-rclated pathologies is the fact that it is frequently combined with other substances. This review focuses on its potential toxicity. The following subjects are discussed: pharmacologic parameters; physico-chemical features; exposure; clinical trials; experimental research; diagnosis; tolerance and dependence; acute and chronic effects; neurotoxicity; teratogenicity; psychiatric disorders; carcinogenicity; and treatment. It is concluded that is important more research on larger population samples with a view to better definition of the consequences of chronic use should be undertaken.

Keywords: Toluene, toxicity. Occupacional exposure. Sustance abuse.

\section{Referências Bibliográficas}

1. ANDERSON, H.R.; MACNAIR, R.S.; RAMSEY, J.D. Deaths from abuse of volatile sustances: a national epidemiological study. BMJ, 290:304-7, 1985.

2. ANDIREW'S, L.S. \& SNYDER, R. Toxic effects of solvents and vapors. In: Amdur, M.O.; Doull, J.; Klaasen, C.D., ed. Casavett \& Doulls toxilogy: the basic science of poisons. $4^{\text {th }}$ ed., New York, Pergamon Press, 1991. p.681-722

3 ADDICTION RESEARCH FOUNDATION (ARF) Drugs in Ontario.Toronto, 1990.

4. ASIITON, C.II. Solvent abuse. BMJ, 300:135-6, 1990.

5 BARNES, G.E. Solvent abuse: a review. Int. J. Addict., 14:1-26, 1979

6. BARROS, H.M.T.; TANNILAUSER, M.; TANNILAUSER, S.L. As doenças de Vincent Van Gogh. Rev. Pesq. Méd., 24:147, 1990.

7. CARLINI, E.A.; CARLINI-COTRIM, B.; MONTEIRO, M.G. Abuso de solventes voláteis: aspectos epideniológicos médico-psicológicos e experimentais. Rev. Assoc. Med. Bras., 34:61.8, 1988.

8. CARLINI, E.A.;CARLINI-COTRIM,B.; SILVA-FILHO, A.R.;BARBOSA, M.T.S. II Levantamento nacional sobre uso de psicotrópicos em estudantes de $1^{8}$ e $2^{2}$ graus em 1989. São Paulo, Centro Brasileiro de Informações sobre Drogas Psicotrópicas (CEBRID)/Escola Paulista de Medicina, s.d.

9. CIIERRY, N.M.; LABRECHE, F.P.;MCDONALD, J.C. Organic brain damage and occupational solvent exposure. Br. J. Ind. Med., 49:776-81, 1992.

10. COIIEN, S. Abuse of inhalants. In: Pradhan, S.N., ed. Diug abuse: clinical and basic aspects., Saint Louis Mosby Company, 1977. p. 290-302.

11. CRONK,S.L.; BARKLEY, D.E.II.; FARREL, M.F. Respiratory arrest after solvent abuse.BMJ, 290:897-8, 1985.

12 CUNNINGHAM, S.R.; DAIZELL, G.W.N.; McGIRR, P; KILN, M.M.Myocardial infarction and primary ventricular fibrillation after glue sniffing. $B M J$, 294:739-40, 1987.

13. DINWIDDIE,S.II.; REICH, T,; CLONINGER, C.R. Solvent use and psichiatric comorbidity. Br.J. Addict., 85: $1647.56,1990$.

14. ECHEVERRIA, D.; FINE, L.; LANGOLF, G.; SCHORK, T.; SAMPAIO, C. Acute behevioural comparisons of toluene and ethanol in human subjects. Br. J. Ind. Med., 48:750-61, 1991

15. EVANS, E.B.\& BALSTER, R.L. CNS depressant effects of 
volatile organic solvents. Newrosci. Biobehav. Rev., 15:233-41, 1991 .

16.FILIEY, C.M.; IIEATON, R.K.; ROSENBERG, N.L. White matter dementia in chronic tolucne abuse. Nearo$\log y, 40: 532 \cdot 4,1990$.

17. FLANAGAN, R.J.; MEREdITII, T'J.; RAMSEY, J.D. Volatile substance abuse. In: Glass, I.B., ed. The infernational handbook of addiction behaviour. London, Tavistok/Routkdge, 1991. p.100-6.

18. FORSTER,L.M.K.; BARROS, II.MI'T; TANNIIAUSER, S.L.; TANNILUSER M. Meninos ma rua: reliçĩo entre abuso de drogas e atividades ilficilas. Rev. $A B P-A P A L, 14: 115 \cdot 20,1992$

19. FUXE, K.; MARTIRE, M.; VON FUI.ER, G.; AGNATI, L.F.; IIANSSON, T.; ANTIIRSSON , K.; GUSTAISSSON, J.A.; ILSSFSTRAND, A liffects of subacule treatment with toluene on cercbrocortical allit-e-beta-adrenergic receptors in the rat. Evidence for an increased number and a reduce affinity of beta-adrenergic receptors. Acta Physiol. Scand., 130:307-11, 1987.

20. GRABSKI, D.A. Toluene sniffing producing cerebellar degeneration. Am.J. Psichiatry, 118:161-2, 1981.

21. ILALL, D.M.B.; RAMSEY, J.; SCIIWART'Z, M.S.; DOOKUN, D. Neuropatlyy in a petrol suiffer. Arch. Dis. Child., 61: 900-1, 1986 .

22. KAELAN, C.; ILARPLR, C.; VILIRA, B.I. Acule encephilopathy and death due to petrol sniffing: neuropathological findings. Aust. N.Z. J. Med., 16: 80 i-7, 1986.

23. KNISEL.Y, J.S.;REES, D.C.; BAl.STLR, R.I. Discriminative stimulus properties of toluene in the rat. Netroloxicol. Teratol, 12: 129-33, 1990.

24. KING, M.D.; DAY, R.E.; OLIVIR, J.S.;LUSII, M.; WATSON, J.M. Solvent encephalopathy. B.IIJ, 283:663-5, 1991.

25. KOROBKIN, R.; ASBURY, A.K.; SUMNER, A.J.; NIEI. SEN, S.L. Glue-snilfing neuropathy. Arch. nemol, 32:158-62, 1975 .

26. LADEFOGED, O.; STRANGE, P.; MOILER, A.; LAM, II.R.; OSTERGAMRD, G.; LARSIN, J J.; ARLIIENSOBORG, P. Irteversible eflects in rats of toluene (inhalation) exposure for six months. Pharmacol. Toxicol., 68:381.90, 1991

27. MINISTÉRIO DA SAÚDE. Sccretaria geral. Conscitho Nacional de Saude. Consumo de drogas psicolrópicas no Brasil, em 1987. Brasiliat, Centro de Documentação do Ministério da Satúdc, 198). (Sćric C: estudos e projctos, 5).

28. NG, T.P.; TOO, S.C.; YOONG, T.Menstrual function in workers exposed to toluene. Bi. J. Ind. Med., 49:799-803, 1992 .

29. NOVAK, A. et al. The deliberate inhalation of volatile substances. J. Psychodelic.Drugs, 12:105-11, 1980.

30. PEDIROZO, M. de F.M. \& SIQULIRA, M.E.P.B. de Solventes de cola: abuso e efeitos nocivos à saúde. Rev. Saúde Pública, 23:336-10, 1989).

31. PRYOR, G.T. A tolucne-induced molor syndrome in rats resembling that seen in some human solvent abusers. Neuroloxicol. Teratol. 13:387-400, 1991.

32. PRYOR, G.;RELERT, C.; KASSAY, K; KUIPLLR, I I, GORDON, $R$. The hearing loss associated with exposure to toluene is not caused by a metabolite. Brain Res. Bull., 27:109-13, 1991.

33. REES, D.C.; KNISELY, J.S.; IBRIEEN, T.J.; BALST'ER, R.L. Toluene, halothane, 1,1,1- Trichlorocthane and oxazepan produce ethanol - like discriminative sti- mulus cliects in mice. J. Phammacol. Exp. Ther: 243: $931 \cdot 7,1987$.

34. RON, M.A. Volitile substance abuse: a review of possible long-tcrm neurological, intellectual and psychiatric sequelac. J. Psychialry, 148:235-46, 1986.

35. ROSENBI:RG, N.L.:KLEINSCHIMIDT-DEMLASIERS, B.K. DAVIS,K.A.;DREISBACII, J.N.; IIORYES, J.T.; FILI.IY, C.M. Toluene abuse causes difluse central nervous system white matter changes. Ann. Neterol., 23:611-1, 1988.

36. SCIUCKI'T,M.Colas, solventes c acrosóis. In: Schukit, M. Abuso de álcool e drogas: uma orientação clínica ao diagnóstico e tratamento. Porto Alegre, Artes Méclicas, 1991. p. 2209.

37. SIIO'l'SUKI, N.; SILVA-lILIIO, A.R.; MON'TEIRO, M.G.; SOUZA-I:ORMIGONI, M.L.O. Ioxicologia dos solventes de cola: Il. IEfcitos bioquímicos, hematológjcos, anatomopatológicos e teratogénicos da mistura de colucno e n-hexano em animais de laboratório.Rev. Pesq. Méd., 23:95-100, 1989).

38. SILVA-FILIIO,A.R.;MONTIIRO,M.G.: SOUZA-FORMIGONI, M.L.O.; SIIIO'ISUKI,N. 'Toxicologia dos solventes de cola: I. Efertos comportamentais da mistura de lolucno e n-hexano em animais de laboratório. Rev. l'esif. Hédl, 23:85-9)-́, 1989.

39. STRIICIIER, H.Z.; GABOW, P.A.; MOSS, A.II.; KONO, D.; KAllINY, W.D. Syndromes of tolucne sniffing in adults. Ann. Inlern. Med.; 94:758-62, 1981.

40. SULIVAN, J.B. \& VAN ERT, M. Alkybenzene solvents and aromatic compounds.In: Sullivan, J.B. \& Kricger,G.R., ed. Lazadous materials loxicology clinical principles of environmental health. Baltimore, Willian \& Wilkins, 1992. p. 1086-104.

41. TARDII, R.; LAPARË, S.; PLAA, G.L., BRODEUR, J.Effect of simultancous exposure to toluene and xylene on their respective biological indices in humans. Int. Arch. Occup. Lnviron. Heallh, 63:279-81, 1991.

12. TOUZI:AU, D.A. A perspectiva farmacológicar. In: Bergerct, J. \& Lcblanc, J. Toxicomanias: uma visão mullirlisciplinar: Porto Alegre, Artes Médicas, 1991.p. 19-5.1.

43. TWILG, M. \& OISON, K.R. Foluene and xylene. In: Olson, K.R., ed. Poisoning \& drug overdose. Norwalk, Aplleton \& lange, 1990. p.281-2.

4.1. VONLULIR, G, OGRIN, S.O,; BONDY, S.C.; MCKEE, M.; WARNER, M.; GUSTASSSON, J.A.; ENEROTI, P.; IUUXE, K. Subacute exposure to low concentrations of toluene affects dopamine-mediated locomotor activity in the rat loxicology, 67:333-19, 1991.

45. WIELCI, L.; KIRSIINLR,II.; IIEATII , A.;GILILAND, R.; BROYLES, S. Chronic ncuropsychological and neurological impairment following acule exposure to a solvent mixtute of toluche and methyl cthyl ketone (MLK). Clin. Toxicol, 29:435-15, 1991.

46. WIIIT, R.F.;FLDMAN, R.G,; 'TRAVERS,P.II. Neurobehaviomal cflects of toxicity due to metals, solvents, and insecticides.Clin. Nourophamacol., 13:392$112,1990$.

47. WISLMAN,M.N. \& BANIM, S. "Glue Sniffer's" heart? B.IJ, 294:739, 1985 .

Recebido para publicação em 27.7.1993

Reapresentado em 3.12.1993

Aprovado para publicação em 20.1.1994 